\title{
Urbanicity of place of birth and symptoms of psychosis, depression and anxiety in Uganda
}

\author{
Patric Lundberg, Elizabeth Cantor-Graae, Godfrey Rukundo, Schola Ashaba and Per-Olof Östergren
}

\section{Background}

The mechanism underlying the association between urban birth/upbringing and increased schizophrenia risk is unknown. This study explored whether an urban effect might be present in a low-income country setting, where the 'urban' environment may have radically different components, for example urban architecture, pollution levels or social cohesion.

\section{Aims}

To investigate the potential association of urbanicity of place of birth and symptoms of psychosis, depression and anxiety in Uganda.

\section{Method}

Ugandans aged 18-30 years ( $n=646)$ were interviewed using the Peters et al Delusions Inventory (PDI-21), the Hopkins Symptoms Checklist (HSCL-25) and psychoticism items from the Symptoms Checklist 90-items version (SCL-90) in Mbarara and Kampala districts and asked about their birthplace.

\section{Results}

Urban birth (but not semi-urban) was associated with more lifetime psychotic experiences, especially grandiosity, and more symptoms of psychosis, depression and anxiety during the past week.

\section{Conclusions}

The urban risk factor for schizophrenia may be universally present across different levels of human development, albeit the nature of the mechanism remains elusive.

\section{Declaration of interest}

None.
Urban birth/upbringing is a well-established risk factor for schizophrenia, ${ }^{1}$ yet little is known about the underlying mechanism. A possible strategy for uncovering candidate explanatory factors may be the investigation of urban-rural differences in psychotic experiences in low-income country settings. Urban centres in lowincome countries may have radically different components in terms of, for example, urban architecture, pollution levels and social cohesion. For instance, $72 \%$ of urban residents in Sub-Saharan Africa live in 'slum households', as defined by the United Nations. ${ }^{2}$

A pilot study in Uganda was the first to assess urban-rural differences in psychotic experiences in a low-income setting, with results indicating an urban effect in the studied sample. ${ }^{3}$ The current study examined the relationship between urbanicity of place of birth and symptoms of psychosis, depression and anxiety in a larger sample of young Ugandans including a broader spectrum of population density levels.

\section{Method}

\section{Setting}

Uganda is mainly a rural country with urban dwellers representing only $12 \%$ of the total population. Urban-rural differences in development indicators are marked, for example in terms of the percentage of households in the lowest wealth quintile (urban $3 \% v$. rural $23 \%$ ), the percentage of households having access to an improved water source $(89 \% v .63 \%)$, the adult female literacy rate $(82 \% v .51 \%)$, and the percentage of households possessing a mobile telephone (53\% v. $10 \%){ }^{4}$ Kampala is the only city, with 1189142 inhabitants (census 2002). Gulu, the second largest centre of population, has only 119430 inhabitants. In order to obtain a maximal range in the level of urbanicity at birth, participants residing in Kampala city, Mbarara town (district capital, population 69363) and in 21 villages in rural Mbarara district in south-west Uganda were interviewed about their mental health status and asked about their birthplace.

\section{Participants}

Sampling was performed in nine study areas: Central, Kawempe and Nakawa divisions in Kampala city, Kakoba, Nyamitanga and Kamukuzi divisions in Mbarara town, and Rubindi, Rubaya and Kakoma subcounties in rural Mbarara district. A two-stage probability sampling method was employed at each of these nine study areas. The primary sampling unit was defined as the lowest administrative unit in Uganda (i.e. the Local Council 1), corresponding to villages in rural areas and neighbourhoods in urban/ semi-urban areas. First, using a map of each study area, seven random points were selected, each point corresponding to a neighbourhood or a village (i.e. probability not proportional to population size). In Kampala city, where economic development varied greatly within study areas, this random selection of seven neighbourhoods was stratified for the neighbourhoods' economic status (i.e. four 'high', three 'middle/low'), based on the local knowledge of G.R. and S.A. Systematic sampling was then performed within each primary sampling unit: a central location was selected in the village or neighbourhood, from where a random direction was obtained spinning a pencil. In that direction, towards the limits of the primary sampling unit, every third household was visited, and all eligible individuals at home at the time of the visit were interviewed. Eligible individuals were people aged between 18 and 30 years, not reporting or displaying overt signs of severe mental or physical illness, or under the influence of alcohol or drugs at the time of contact. In the urban/semi-urban settings, interviews were conducted in the afternoon maximising the number of participants at home, whereas in the rural villages, where people more often work at home, interviews were conducted during the entire day. If no eligible person was at home the next household was visited, and after that, every third household. Follow-up visits were not performed. Households were visited until ten participants had been interviewed at each primary sampling unit, yielding an estimated number of $9 \times 7 \times 10=630$ participants in total. This 
approximate sample size was the largest possible given the financial and practical constraints of the study, and was thus not predetermined through sample size calculations.

\section{Questionnaire}

Sociodemographic background data was collected at the beginning of the interview. The hypothesised exposure 'urbanicity of place of birth', was operationally defined as the parents' place of residence at the time of the participant's birth. Based on the participants' responses, exposure was graded into three levels: 'urban' (Kampala city), 'semi-urban' (settlements classified as municipal or town councils, i.e. having $>25000$ inhabitants, as per the Local Government Act of 1997), and 'rural' (settlements classified as villages, i.e. having $\leqslant 25000$ inhabitants).

The main outcome measures were lifetime experience of delusional ideation and recent experience (past week) of symptoms of psychosis, depression and anxiety. The Peters et al Delusions Inventory (PDI-21) assesses the lifetime experience of delusional ideation in participants from the normal population. ${ }^{5}$ It contains 21 items (yes/no) distributed across 11 components (religiosity, persecution, grandiosity, paranormal beliefs, thought disturbances, suspiciousness, catastrophic ideation and thought broadcast, negative self, paranoid ideation, ideation of reference and influence, depersonalisation). Each item positively endorsed is followed by a series of five-point scales probing for levels of associated distress, preoccupation and conviction respectively. The PDI-21 has shown good reliability and validity in Europe ${ }^{5,6}$ and was recently used in Mbarara town/district ${ }^{3}$ and in Kampala ${ }^{7}$ yielding results indicative of cross-cultural validity in these Ugandan settings.

The Hopkins Symptoms Checklist (HSCL-25) measures symptoms of anxiety and depression during the past week. ${ }^{8}$ It contains 15 depression items and 10 anxiety items, the response to each item graded from 1 'not at all' to 4 'extremely'. The HSCL-25 has been widely translated and successfully used in a variety of cultural contexts. ${ }^{8,9}$ Bolton \& Ndogoni validated the depression section of the questionnaire in Masaka and Rakai districts in Uganda (neighbouring Mbarara district) using ethnographical methods. ${ }^{10}$ In their local HSCL-dep version they kept all but one of the original fifteen HSCL-25 items, indicating cross-cultural robustness of the HSCL-25 instrument.

The Symptoms Checklist 90-items version (SCL-90) subscale for psychoticism measures psychotic symptoms during the past week. ${ }^{11}$ It consists of 10 items assessing thought disturbances, auditory hallucinations, feelings of loneliness or guilt and feelings that something is wrong with one's body or mind. In the SCL-90 the response to each item is graded from 0 'not at all' to 4 'extremely'. However, in order to simplify it for the respondents, we adopted the same four-graded scale for psychoticism as that used in the HSCL-25 (see above), yielding the modified psychoticism measure SCL-psych.

Information regarding history of severe mental disorder in the participant or in a first- or second-degree relative was collected at the end of the interview, probing for people with 'mental problems' or 'mental breakdown'.

\section{Instrument translation and pre-testing}

The study instrument was translated from English into Runyankore and Luganda and independently back-translated. The two versions were compared and necessary adjustments made (P.L., G.R., S.A. and translators). Care was taken in order not to introduce culturally alien notions or expressions, while preserving the core relevant to the explored psychopathology of each question. For instance, translating PDI-21 item 9, probing for beliefs in telepathy, 'communicate telepathically' was replaced by 'communicate silently in one's thoughts without seeing each other and without using any device'. Five group discussions (P.L. and G.R. plus two to four participants, purposively selected in Mbarara town) were conducted in order to explore the crosscultural validity of the symptoms and of the illness concepts represented by these symptoms. Case vignettes of people experiencing symptoms of depression, anxiety and psychosis were constructed using the corresponding items from the HSCL-25 or the SCL-psych. Participants were then asked: whether they had met or heard about any person behaving or feeling that way; whether it was commonly encountered in society; how they believed the condition was experienced by the person (e.g. distressful/not distressful); and whether seeking help was required.

Overall, although not a formal test of cross-cultural validity and based on a small number of participants, the results obtained from these exploratory discussions suggested that the HSCL-25 and SCL-psych items corresponded to well-known conditions present in society (psychosis less commonly found) recognised as distressful and often requiring help from God, friends, traditional healers, psychological counsellors or Western medicine. The final version of the questionnaire was pre-tested on people not participating in the study and found to be acceptable.

\section{Procedure}

Data collection took place between September 2004 and June 2005. The study team consisted of G.R., S.A. and seven research assistants. The research assistants pursued or had completed university training in psychology, sociology or medicine. Initial co-training was performed and continuous supervision given throughout the fieldwork. The study was presented to the potential participants as a study about health, beliefs and experiences. Confidentiality and anonymity of respondents and their right to decline was carefully explained. Refusal to participate and/or to complete the entire questionnaire was rare $(<5 \%$ of those approached). Interviews were conducted in privacy. Questions were presented verbally and the responses registered by the interviewer. Clarifications were readily given for any question arising during the interview. Interviewing languages were English (all sites) and Runyankore (Mbarara town and district) or Luganda (Kampala city), according to the proficiency of the respondent. Data was entered into an SPSS file by the research assistants and cross-checked by G.R. and S.A. Ethical permission for the study was obtained from the ethical committee at the Mbarara University of Science and Technology.

\section{Data analysis}

Sociodemographic background variables were: age (continuous), gender (female $v$. male), education $(\leqslant 7$ years $v .>7$ years of schooling, i.e. up to primary school $v$. more than primary school), socioeconomic status (high $v$. middle/low), and civil status (married/cohabiting $v$. no partner). Socioeconomic status was based on the participant's occupation and categorised according to norms appropriate for Uganda, with 'high' representing persons with occupations requiring higher education, relatively more economically rewarding or associated with higher prestige (e.g. engineers, teachers, nurses, businessmen, civil servants), and 'middle/low' representing farmers, unskilled workers, self-employed, unemployed, etc.

Personal and family histories of severe mental disorder (scored as yes $v$. no for both variables) were based on responses to the probe questions asked at the end of the interview. Reported 
potential psychiatric symptoms (the most common being social withdrawal, violent behaviour, undressing in public and wandering) in the past, in the participant and in the participant's first- or second-degree biological relatives were investigated, and a probable diagnosis (G.R. and S.A.) made concerning past severe mental disorder (i.e. major depression, mania, psychosis) in the person and in the relatives.

Urbanicity of place of birth was coded as a categorical variable, with 0 for a rural birth, 1 for semi-urban birth and 2 for an urban birth (for definitions of 'urban', etc., see under Questionnaire, p. 157).

Two outcome measures were calculated from the PDI-21: PDI-yes, i.e. the total number of endorsed items (maximum 21), and PDI-severity, summarising the total scores of the severity subscales: distress, preoccupation and conviction (three subscales, each with a maximum score of 105) yielding a maximum score of 315. Two outcome measures were calculated from the HSCL-25: 'HSCL-dep' (the total score of the depression items; 15 items, graded from 1 to 4, maximum 60) and 'HSCL-anx' (the sum of the scores of the anxiety items; 10 items, graded from 1 to 4 , maximum 40). The outcome measure SCL-psych represented the total score of the 10 psychoticism items from the SCL-90 (having a modified range from 1 to 4 , maximum 40 ).

\section{Statistical analysis}

The rural birth subgroup was used as a reference group to which semi-urban and urban subgroups were compared. Subgroup comparisons were performed using the Mann-Whitney $U$-test for continuous variables (outcome measures were not normally distributed) and the $\chi^{2}$-test for categorical variables. Associations between outcome measures were analysed using Spearman's rank correlations. A logistic regression model was constructed in order to adjust for potential confounding by background factors, with age, gender and education a priori included as covariates. For the purpose of these analyses, educational level rather than current occupational status was used to reflect socioeconomic status, given that decreased mental functioning (e.g. schizotypy) can influence current occupational status. Also, information concerning parental socioeconomic status was not available. Moreover, socioeconomic status was strongly associated $\left(\chi^{2}\right.$-test) with education. Personal history of mental illness was omitted from the model given that only 12 participants had endorsed this item. Civil status and family history of mental illness were included in the model, since they were highly significant outcome predictors. Outcome measures (PDI-yes, PDI-severity, SCL-psych, HSCL-dep and HSCL-anx) were dichotomised into 'high' $v$. 'low' (median split) given the low number of items underlying each measure (e.g. SCL-psych: 10 items). Significance level was accepted at $P<0.05$, two tailed. $P$-values approaching significance $(P<0.10)$ were reported only for results concerning the main association under study, i.e. between urbanicity of place of birth and outcome. Statistical analyses were performed using SPSS version 12.0 for Windows.

\section{Results}

The total sample consisted of 646 participants. Overall, 64 people reported an urban place of birth, 100 a semi-urban one, and 482 a rural one. In total, 217 participants reported an urban place of residence (of whom 52 reported an urban place of birth, 66 a semi-urban one and 99 a rural one), 217 reported a semi-urban place of residence (of whom 8 reported an urban place of birth, 33 a semi-urban one and 176 a rural one) and 212 a rural place of residence (of whom 4 reported an urban place of birth, 1 a semi-urban one and 207 a rural one). Background characteristics of the entire sample are shown in Table 1.
In the entire sample, means (s.d.) for the outcome measures were: PDI-yes, 6.9 (s.d.=4.5); PDI-severity, 58.2 (s.d.=41.5); SCL-psych, 13.0 (s.d.=3.7); HSCL-dep, 23.0 (s.d.=6.5); and HSCL-anx, 14.0 (s.d.=4.9).

\section{Distribution of background factors across subgroups}

Participants born in urban and semi-urban areas had significantly higher socioeconomic status than participants born in rural areas (urban $v$. rural $\chi^{2}=15.8, P<0.001$; semi-urban $v$. rural $\chi^{2}=16.6$, $P<0.001)$. Levels of education were also higher in these subgroups compared with the rural birth group (urban $v$. rural $\chi^{2}=21.7$, $P<0.001$; semi-urban $v$. rural $\chi^{2}=27.5, P<0.001$ ). The distribution of gender and age did not differ significantly between the subgroups. The urban, but not the semi-urban, subgroup had significantly more unmarried/not cohabiting individuals $v$. the rural subgroup (urban $v$. rural $\chi^{2}=6.6, P<0.05$ ). Of the 12 individuals with a positive personal history of severe mental disorder none were born in an urban area, 3 in a semi-urban area and 9 in a rural area. The distribution of people with a positive family history of severe mental disorder was not significantly different between the subgroups (ratio positive/negative in urban birth group: 17/47; semi-urban: 29/71; rural 99/381).

\section{Associations between outcome measures}

All five outcome measures were significantly intercorrelated: PDIyes and PDI-severity $(r=0.96)$, PDI-yes and SCL-psych $(r=0.58)$, PDI-yes and HSCL-dep $(r=0.63)$, PDI-yes and HSCL-anx $(r=0.53)$, PDI-severity and SCL-psych $(r=0.63)$, PDI-severity and HSCL-dep $(r=0.68)$, PDI-severity and HSCL-anx $(r=0.58)$, SCL-psych and HSCL-dep $(r=0.77)$, SCL-psych and HSCL-anx $(r=0.72)$, and HSCL-dep and HSCL-anx $(r=0.76),(P<0.001$ for all measures $)$.

\begin{tabular}{|c|c|}
\hline \multicolumn{2}{|l|}{ Characteristic } \\
\hline Age, years: mean (s.d.) & $24.2(3.77)$ \\
\hline \multicolumn{2}{|l|}{ Gender, $n(\%)$} \\
\hline Male & $334(51.7)$ \\
\hline Female & $312(48.3)$ \\
\hline \multicolumn{2}{|l|}{ 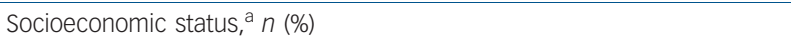 } \\
\hline High & $210(33.5)$ \\
\hline Middle/low & $417(66.5)$ \\
\hline \multicolumn{2}{|l|}{ Educational level, ${ }^{\mathrm{b}} \mathrm{n}(\%)$} \\
\hline Primary school ( $\leqslant 7$ years) & 207 (32.2) \\
\hline Secondary school (>7 years) & $435(67.8)$ \\
\hline \multicolumn{2}{|l|}{ Civil status, ${ }^{\mathrm{c}} n(\%)$} \\
\hline Married or cohabiting & $286(44.5)$ \\
\hline No partner & $357(55.5)$ \\
\hline \multicolumn{2}{|l|}{ Urbanicity of place of birth, $n(\%)$} \\
\hline Urban & $64(9.9)$ \\
\hline Semi-urban & $100(15.5)$ \\
\hline Rural & $482(74.6)$ \\
\hline \multicolumn{2}{|l|}{ Personal history of severe mental illness, ${ }^{d} n(\%)$} \\
\hline Probable diagnosis made in participant & $12(1.9)$ \\
\hline Probable diagnosis not made in participant & $633(98.1)$ \\
\hline \multicolumn{2}{|l|}{ Family history of severe mental illness, ${ }^{e} n(\%)$} \\
\hline Probable diagnosis made in family & $145(22.5)$ \\
\hline Probable diagnosis not made in family & $499(77.5)$ \\
\hline \multicolumn{2}{|l|}{$\begin{array}{l}\text { a. Information was missing for } 19 \text { participants. } \\
\text { b. Information was missing for } 4 \text { participants. } \\
\text { c. Information was missing for } 3 \text { participants. } \\
\text { d. Information was missing for } 1 \text { participant. } \\
\text { e. Information was missing for } 2 \text { participants. }\end{array}$} \\
\hline
\end{tabular}




\section{Outcome in relationship to urbanicity and other background characteristics}

Participants born in urban areas had significantly higher PDI-yes and HSCL-anx scores and borderline significantly higher PDIseverity scores than participants born in rural areas (PDI-yes, $z=-2.2, P=0.03$; HSCL-anx, $z=-2.5, P=0.01$; PDI-severity, $z=-1.91, P=0.06$ ). All other comparisons between the urban $v$. rural birth and the semi-urban $v$. rural birth subgroups regarding the five outcome measures were non-significant (Table 2).

In order to rule out confounding by background factors, the relationship between urbanicity of place of birth and outcome was further examined using logistic regression analysis. In the final model (see Statistical analysis for covariate selection) urban birth $v$. rural, but not semi-urban birth $v$. rural, was significantly associated with high PDI-yes, SCL-psych, HSCL-dep and HSCL-anx scores, after simultaneous adjustment for all covariates (Table 3).

Female gender was associated with high HSCL-dep and HSCL-anx scores, low level of education was associated with high HSCL-dep score, family history of severe mental disorder was associated with high PDI-yes, PDI-severity, HSCL-dep and HSCL-anx scores, and being married or cohabiting with a partner was associated with high SCL-psych, HSCL-dep, HSCL-anx scores (Table 3 ). Age was not significantly associated with any outcome measures.

\section{Profiles of PDI-21 response frequencies in relationship to urbanicity}

Given our previous finding that grandiose ideation in particular (in contrast to for example paranoid ideation) was increased in a semi-urban $v$. rural sample in south-west Uganda, ${ }^{3}$ we further investigated potential differences between urban $v$. rural and semi-urban $v$. rural subgroups in response frequency of the individual PDI-21 items. Participants with urban ( $v$. rural) place of birth significantly more often endorsed PDI-21 item 6 (being destined to be someone very important: $\left.\chi^{2}=8.7, P=0.003\right)$, item 7 (being a very special or unusual person: $\chi^{2}=8.9, P=0.003$ ), item 11 (being chosen by God in some way: $\chi^{2}=12.5, P<0.001$ ) and item 12 (believe in the power of witchcraft: $\chi^{2}=5.2, P=0.02$ ). Individuals with semi-urban ( $v$. rural) place of birth significantly more often endorsed item 2 (things in magazines or on TV are written especially for you: $\chi^{2}=4.8, P=0.03$ ), item 6 (being destined to be someone very important: $\left.\chi^{2}=4.1, P<0.05\right)$ and item 11 (being chosen by God in some way: $\chi^{2}=6.5, P=0.01$ ).

\section{Discussion}

\section{Main findings}

Participants born in urban areas had experienced significantly more psychotic symptoms (especially grandiosity) during their lifetime than those born in rural areas, and more symptoms of psychosis, depression and anxiety during the past week. There were no significant differences between participants born in semi-urban $v$. rural areas on these measures.

Women had increased depression and anxiety scores. A low level of education was associated with more depressive symptoms. Age was not a significant outcome predictor, in contrast to previous studies in Uganda where depression was associated with higher age $\mathrm{e}^{12}$ and psychotic experiences with younger age, ${ }^{3,7}$ and to findings in Europe of increased prevalence of psychotic experiences during adolescence and early adulthood compared with later in life. ${ }^{13}$ It should be noted however that the age range in the current study was narrow (18-30 years). Family history of severe mental disorder was associated with more lifetime experiences of psychotic symptoms and with increased levels of

\begin{tabular}{|c|c|c|c|c|c|}
\hline Place of birth & $\begin{array}{c}\text { PDI-yes } \\
\text { Mean (s.d.) }\end{array}$ & $\begin{array}{l}\text { PDI-severity } \\
\text { Mean (s.d.) }\end{array}$ & $\begin{array}{l}\text { SCL-psych } \\
\text { Mean (s.d.) }\end{array}$ & $\begin{array}{l}\text { HSCL-dep } \\
\text { Mean (s.d.) }\end{array}$ & $\begin{array}{l}\text { HSCL-anx } \\
\text { Mean (s.d.) }\end{array}$ \\
\hline Rural, $n=482$ & $6.76(4.68)$ & $57.19(42.81)$ & 13.04 (3.81) & $23.01(6.48)$ & 13.85 (4.76) \\
\hline Semi-urban, $n=100$ & $7.01(3.56)$ & $57.32(35.02)$ & 12.48 (3.33) & $22.43(6.24)$ & $13.83(5.13)$ \\
\hline Urban, $n=64$ & $7.84(4.01)^{*}$ & $66.83(40.56)$ & $13.37(3.47)$ & $23.91(6.91)$ & $15.41(5.32)^{*}$ \\
\hline
\end{tabular}

\begin{tabular}{|c|c|c|c|c|c|}
\hline Explanatory variable & $\begin{array}{l}\text { PDI-yes } \\
\text { Adjusted OR } \\
(95 \% \mathrm{Cl})\end{array}$ & $\begin{array}{l}\text { PDI-severity } \\
\text { Adjusted OR } \\
\quad(95 \% \mathrm{Cl})\end{array}$ & $\begin{array}{l}\text { SCL-psych } \\
\text { Adjusted OR } \\
(95 \% \mathrm{Cl})\end{array}$ & $\begin{array}{c}\text { HSCL-dep } \\
\text { Adjusted OR } \\
(95 \% \mathrm{Cl})\end{array}$ & $\begin{array}{c}\text { HSCL-anx } \\
\text { Adjusted OR } \\
(95 \% \mathrm{Cl})\end{array}$ \\
\hline \multicolumn{6}{|l|}{ Birth } \\
\hline Rural (reference) & 1.0 & 1.0 & 1.0 & 1.0 & 1.0 \\
\hline Semi-urban & $1.2(0.8-1.9)$ & $1.0(0.6-1.6)$ & $0.7(0.4-1.1)$ & $1.1(0.7-1.7)$ & $1.0(0.6-1.6)$ \\
\hline Urban & $2.1(1.2-3.7)^{\star *}$ & $1.4(0.8-2.4)$ & $1.9(1.1-3.3)^{*}$ & $1.9(1.1-3.5)^{*}$ & $1.8(1.0-3.2)^{*}$ \\
\hline Age (continuous) & $1.0(1.0-1.1)$ & $1.0(1.0-1.1)$ & $1.0(1.0-1.0)$ & $1.0(1.0-1.1)$ & $1.0(1.0-1.1)$ \\
\hline Gender (female/male) & $1.2(0.9-1.7)$ & $1.1(0.8-1.5)$ & $1.2(0.9-1.7)$ & $1.8(1.3-2.5)^{\star *}$ & $1.5(1.1-2.0)^{*}$ \\
\hline Education ( $\leqslant />7$ years) & $1.2(0.8-1.7)$ & $1.1(0.8-1.6)$ & $1.3(0.9-1.9)$ & $1.9(1.3-2.7)^{\star *}$ & $1.2(0.8-1.7)$ \\
\hline Family history (yes/no) & $2.1(1.4-3.1)^{\star *}$ & $2.0(1.3-2.9)^{* *}$ & $1.3(0.9-1.9)$ & $1.9(1.3-2.8)^{\star *}$ & $1.5(1.0-2.2)^{*}$ \\
\hline Partner (yes/no) & $1.4(0.9-1.9)$ & $1.1(0.8-1.6)$ & $2.0(1.4-2.9)^{* *}$ & $1.9(1.3-2.7)^{\star *}$ & $1.6(1.1-2.3)^{*}$ \\
\hline
\end{tabular}


symptoms of depression and anxiety during the past week. Being married/cohabiting with a partner was associated with more (rather than fewer) symptoms of psychosis, depression and anxiety during the past week. All the above associations were obtained using logistic regression analysis with explanatory factors simultaneously adjusted for each other.

\section{Strengths and limitations}

The main exposure measure 'urbanicity of place of birth' was based on participants' reporting and thus could not be verified further. If people with grandiose features preferentially reported an urban birth (perhaps because associated with higher status) a bias could have been introduced into the study. Although possible, there was no obvious benefit for individuals in reporting incorrect information to the study team. Moreover, interviews were conducted by Ugandans, proficient in the local language and knowledgeable about local interpersonal communication codes, decreasing the risk for reporting bias (e.g. social desirability).

'Urbanicity of current residence' was not of primary interest in the study for several reasons: the variable 'current residence' could represent a consequence rather than a cause of an abnormal mental state; information about the length of exposure to current residence was not available; and evidence suggests that the 'urban factor' operates early in life. ${ }^{14-16}$ However, in order to rule out the possibility that the association between urbanicity of place of birth and PDI-yes score was confounded by urbanicity of current residence, an additional logistic regression model was constructed with the latter factor entered as an additional covariate (not shown). The association between urbanicity of place of birth and PDI-yes outcome remained significant in this exploratory model (odds ratio $(\mathrm{OR})=2.25,95 \%$ CI 1.2-4.1, $P=0.008$ ).

Data concerning the number of years lived in different levels of urbanicity during upbringing and/or adulthood was not available. Moreover, adequate information concerning residential mobility before age 15 years was not available, thus the potential influence of this factor on the results could not be investigated, as has been done previously in studies of urbanicity and schizophrenia. ${ }^{15}$

The information concerning personal and family history of severe mental illness was not validated, potentially resulting in misclassification of, for example, epilepsy as a mental illness.

We studied psychotic symptoms in the general population based on the schizophrenia continuum hypothesis, ${ }^{17}$ and similarly to van Os et al, ${ }^{18}$ rather than schizophrenic 'caseness'. Although the extent to which symptoms are predictive of future disorder remains uncertain in the current context, the study of symptoms arguably decreases the risk for cross-cultural fallacy since diagnosing involves a subjective interpretation of the reported symptoms. Moreover, the psychosis, depression and anxiety outcome measures all were intercorrelated, which provides further support for the cross-cultural validity of the methods used.

The nine study areas were purposively selected and the results cannot be generalised to other parts of Uganda. Also, only one study site (Kampala) provided participants reporting urban place of birth. Thus, findings might have been specific to Kampala and not to urban settings in general. However, Kampala is Uganda's only city, and in order to find an urban centre of comparable size, a study site outside of Uganda would have had to be selected (e.g. Nairobi, Kigali), entailing problems of comparability (e.g. cultural distance). Moreover, Mbarara district has a population density and human development index close to the Ugandan average, ${ }^{19}$ and the range of participants' place of birth included all of Uganda, and not only Mbarara and Kampala districts.

Although increased symptom levels were found in the urban birth subgroup, there was no evidence of an effect in the semi-urban subgroup ( $v$. rural). Although the absence of a trend could certainly be regarded as an argument against an urban effect in the current sample, a 'non-linear' relationship between the gradations of urbanicity and psychotic experiences might perhaps not be surprising in Uganda, given the vast difference in urbanisation between Kampala and the rest of the country.

\section{The urban factor in Uganda}

The current study was the first to investigate, and demonstrate, a relationship between urban birth and increased psychotic symptoms in a low-income country. Accepting the limitations, the findings thus suggest that the urban risk factor for psychosis is universally present across different levels of human development. More generally, only one study has previously addressed the potential presence of an urban risk factor for psychosis in low-income countries, ${ }^{3}$ but that study had a small sample size and targeted current residence rather than the person's birthplace.

Although the mechanism(s) underlying the urban effect remains unknown, current research suggests that genetic predisposition may interact with some factor(s) present in the urban environment. ${ }^{1}$ For instance, a familial trait coupled both with urban migration and with increased vulnerability for an urban exposure could potentially explain the associations found ${ }^{20}$ (but see van $\mathrm{Os}^{21}$ ), although results were adjusted for family history of severe mental disorder.

Kampala considerably differs in characteristics from the urban centres in Europe such as Copenhagen where the urban effect has previously been found. ${ }^{15,16}$ Thus, although epidemiological studies alone may not be sufficient to reveal the mechanism underlying the urban effect, ${ }^{22}$ some clues could potentially be found by looking more closely at the 'urban' characteristics indicated in this Ugandan setting in relationship to candidate mechanisms. Increased fetal exposure to Toxoplasma gondii ${ }^{23}$ in Kampala compared with exposure in rural areas is perhaps unlikely given less contact with domestic animals and with soil (e.g. households with earth/sand or earth/dung floors in urban v. rural Uganda: 27 v. 86\%), ${ }^{4}$ although urban agriculture does exist in Kampala. Similarly, the risk for obstetric complications ${ }^{24}$ is arguably decreased in Kampala, for example given a larger proportion of deliveries with a skilled birth attendant in urban v. rural Uganda $(80 \%$ v. $37 \%) .{ }^{4}$ On the other hand, however, maternal exposure to pollution during pregnancy or exposure during childhood may be more frequent in Kampala ${ }^{25}$ than in rural areas and remains a possible explanation, ${ }^{26}$ and cannabis use is an increasing problem in Uganda, potentially contributing to the associations found. ${ }^{27}$

Urbanicity at birth is a proxy for urbanicity during upbringing, and social factors operating during and following childhood/adolescence should also be considered. The amount and complexity of social interactions are clearly larger in urbanised Kampala compared with in rural Ugandan communities, with potential for negative effects for example in socially or cognitively weak individuals. ${ }^{28}$ Urban-rural differences might also be marked in aspects of the everyday social environment, such as neighbourhood social cohesion and fragmentation, ${ }^{29,30}$ although this has not been specifically studied in a Ugandan setting. Moreover, people growing up and living in Kampala, indirectly exposed to the wealth and possibilities of the high-income world (e.g. advertisements, internet cafés, international institutions) but with limited opportunities of status improvement (compare with ethnic minorities in Europe), might be at risk for repeated or continuous experiences of thwarted aspirations and social defeat. ${ }^{31}$ 
The ethnic composition differs between the populations in Mbarara town/district (Bantu tribe: Banyankore) and Kampala (Bantu tribe: Baganda). Schizophrenia risk is associated with ethnicity (especially ethnic minority status) in Europe, ${ }^{32}$ and although the above-mentioned tribes are majority and not minority groups, Kampala does host a more ethnically mixed population, which could hypothetically have contributed to the associations found. Indeed, investigating psychosis-proneness in ethnic minorities in non-Western countries could further the understanding of the migrant effect in schizophrenia.

Finally, it is notable that in the current study an urban effect was found also for symptoms of depression and anxiety, although the literature concerning urban-rural differences in rates of affective disorders is not consistent. ${ }^{33,34}$ However, increasing evidence suggests a central role for emotional dysfunction (i.e. depression and anxiety) in psychosis formation ${ }^{35,36}$ and although speculative, the current data are compatible with the notion that affective symptoms might mediate the effect of urbanicity on psychosis. $^{37}$

The demonstration of an urban effect in a low-income country opens new avenues for investigations of candidate mechanisms underlying the urban risk factor for schizophrenia. Moreover, and perhaps even more importantly, the current findings suggest that the urban factor might be universally present, contributing to considerable suffering and disability across all levels of human development. The global impact of this factor is likely to increase even more, given the rapidly growing urbanisation in the low-income world.

Patric Lundberg, MD, Department of Health Sciences, Lund University, University Hospital UMAS, Malmö, Sweden, and Department of Public Health Sciences, Karolinska Institute, Norrbacka, Stockholm, Sweden; Elizabeth Cantor-Graae, PhD, Department of Health Sciences, Lund University, University Hospital UMAS, Malmö, Sweden; Godfrey Rukundo, MD, Schola Ashaba, MD, Department of Psychiatry, Mbarara University of Science and Technology, Mbarara, Uganda; Per-Olof Östergren, MD, PhD, Department of Health Sciences, Lund University, University Hospital UMAS, Malmö, Sweden

Correspondence: Patric Lundberg, Division of Social Medicine, Department of Public Health Sciences, Karolinska Institute, Norrbacka, $5^{\text {th }}$ floor, S-171 76 , Stockholm, Sweden. Email: patric.lundberg@ki.se

First received 6 Mar 2008, final revision 7 Dec 2008, accepted 5 Feb 2009

\section{Funding}

The study was supported by the Swedish International Development Cooperation Agency (SIDA/SAREC) and the Medical Faculty at Lund University.

\section{Acknowledgements}

The authors thank Dr Jerome Kabakyenga and Gad Ruzaaza for their support and assistance.

\section{References}

1 Krabbendam L, van Os J. Schizophrenia and urbanicity: a major environmental influence - conditional on genetic risk. Schizophr Bull 2005. 31: 795-9.

2 United Nations. Urbanization. Challenges in Sub-Saharan Africa. United Nations Human Settlements Programme, 2005.

3 Lundberg P, Cantor-Graae E, Kabakyenga J, Rukundo G, Östergren PO. Prevalence of delusional ideation in a district in southwest Uganda. Schizophr Res 2004; 71: 27-34.

4 Uganda Bureau of Statistics. Uganda Demographic and Health Survey 2006 Uganda Bureau of Statistics, 2006.

5 Peters E, Joseph S, Garety P. Measurement of delusional ideation in the normal population: introducing the PDI (Peters et al. Delusions Inventory). Schizophr Bull 1999; 25: 553-76.
6 Verdoux H, Maurice-Tison S, Gay B, van Os J, Salamon R, Bourgeois M. A survey of delusional ideation in primary-care patients. Psychol Med 1998; 28: $127-34$

7 Lundberg P, Cantor-Graae E, Kahima M, Östergren PO. Delusional ideation and manic symptoms in potential future emigrants in Uganda. Psychol Med 2007; 37: 505-12.

8 Mollica R, Wyshak G, de Marneffe D, Khuon F, Lavelle J. Indochinese versions of the Hopkins Symptom Checklist-25: a screening instrument for the psychiatric care of refugees. Am J Psychiatry 1987; 144: 497-500.

9 Kaaya S, Fawzi M, Mbwambo J, Lee B, Fawzi W. Validity of the Hopkins Symptom Checklist-25 amongst HIV-positive pregnant women in Tanzania. Acta Psychiatr Scand 2002; 106: 9-19.

10 Bolton $\mathrm{P}, \mathrm{Ndogoni}$ L. Cross-cultural assessment of trauma-related mental illness (Phase II). World Vision Uganda and the Johns Hopkins University, 2001 (http://www.certi.org/publications/policy/ugandafinahreport.htm).

11 Derogatis L, Lipman R, Covi L. SCL-90: an outpatient psychiatric rating scale - preliminary report. Psychopharmacol Bull 1973; 9: 13-28.

12 Bolton P, Wilk C, Ndogoni L. Assessment of depression prevalence in rural Uganda using symptom and function criteria. Soc Psychiatry Psychiatr Epidemiol 2004; 39: 442-7.

13 Verdoux $H$, van Os J, Maurice-Tison S, Gay B, Salamon R, Bourgeois M. Is early adulthood a critical developmental stage for psychosis proneness? A survey of delusional ideation in normal subjects. Schizophr Res 1998; 29: 247-54.

14 Marcelis M, Takei N, van Os J. Urbanization and risk for schizophrenia: does the effect operate before or around the time of illness onset? Psychol Med 1999; 29: 1197-203.

15 Pedersen $\mathrm{C}$, Mortensen P. Evidence of a dose-response relationship between urbanicity during upbringing and schizophrenia risk. Arch Gen Psychiatry 2001; 58: 1039-46.

16 Cantor-Graae E, Pedersen C. Risk of schizophrenia in second-generation immigrants: a Danish population-based cohort study. Psychol Med 2007; 37: 485-94.

17 Johns L, van Os J. The continuity of psychotic experiences in the general population. Clin Psychol Rev 2001; 21: 1125-41.

18 van Os J, Hanssen M, Bijl R, Vollebergh W. Prevalence of psychotic disorder and community level of psychotic symptoms. An urban-rural comparison. Arch Gen Psychiatry 2001; 58: 663-8.

19 United Nations Development Programme. Uganda Human Development Report 2005. United Nations Development Programme, 2005.

20 Pedersen CB, Mortensen PB. Why factors rooted in the family may solely explain the urban-rural differences in schizophrenia risk estimates. Epidemiol Psychiatr Soc 2006; 15: 247-51.

21 van Os J. Commentary on residential location papers by Whitfield et al. (2005) and Willemsen et al. (2005). Twin Res Hum Genet 2005; 8: 318-9.

22 MCGrath J. The surprisingly rich contours of schizophrenia epidemiology Arch Gen Psychiatry 2007; 64: 14-6.

23 Torrey F, Bartko J, Lun ZR, Yolken R. Antibodies to Toxoplasma gondii in patients with schizophrenia: a meta-analysis. Schizophr Bull 2007; 33: 729-36.

24 Cannon $\mathrm{M}$, Jones $\mathrm{P}$, Murray R. Obstetric complications and schizophrenia: historical and meta-analytic review. Am J Psychiatry 2002; 159: 1080-92.

25 Matagi S. Some issues of environmental concern in Kampala, the capital city of Uganda. Environ Monitor Assessment 2002; 77: 121-38.

26 Pedersen C, Raaschou-Nielsen O, Hertel O, Mortensen P. Air pollution from traffic and schizophrenia risk. Schizophr Res 2004; 66: 83-5.

27 Henquet C, Murray R, Linszen D, van Os J. The environment and schizophrenia: the role of cannabis use. Schizophr Bull 2005; 31: 608-12.

28 Weiser M, van Os J, Reichenberg A, Rabinowitz J, Nahon D, Kravitz E, et al. Social and cognitive functioning, urbanicity and risk for schizophrenia. Br J Psychiatry 2007; 191: 320-4.

29 Allardyce J, Gilmour H, Atkinson J, Rapson T, Bishop J, McCreadie RG. Social fragmentation, deprivation and urbanicity: relation to first-admission rates for psychoses. Br J Psychiatry 2005; 187: 401-6.

30 Kirkbide J, Morgan C, Fearon P, Dazzan P, Murray R, Jones P. Neighbourhood-level effects on psychoses: re-examining the role of context. Psychol Med 2007; 37: 1413-25.

31 Selten JP, Cantor-Graae E. Social defeat: risk factor for schizophrenia? Br J Psychiatry 2005; 187: 101-2.

32 Cantor-Graae E, Selten JP. Schizophrenia and migration: a meta-analysis and review. Am J PSychiatry 2005; 162: 12-24. 
33 Sundquist K, Frank G, Sundquist J. Urbanisation and incidence of psychosis and depression: follow-up study of 4.4 million women and men in Sweden. Br J Psychiatry 2004; 184: 293-8.

34 Mortenssen $\mathrm{PB}$, Pedersen $\mathrm{CB}$, Melbye $\mathrm{M}$, Mors $\mathrm{O}$, Ewald $\mathrm{H}$. Individual and familial risk factors for bipolar affective disorders in Denmark. Arch Gen Psychiatry 2003; 60: 1209-15.

35 Freeman D, Garety PA. Connecting neurosis and psychosis: the direct influence of emotion on delusions and hallucinations. Behav Res Ther 2003; 41: $923-47$
36 Freeman D, Gittins M, Pugh K, Antley A, Slater M, Dunn G What makes one person paranoid and another person anxious? The differential prediction of social anxiety and persecutory ideation in an experimental situation. Psychol Med 2008; 38 $1121-32$

37 Ellett L, Freeman D, Garety P. The psychological effect of an urban environment on individuals with persecutory delusions: the Camberwell walk study. Schizophr Res 2008; 99: 77-84.

\section{Psychiatrists in 19th-century fiction}

\section{In a Glass Darkly (1872), J. Sheridan LeFanu}

\section{Fiona Subotsky}

Joseph Sheridan Le Fanu (1814-1873) is another literary Dubliner. Having studied law at Trinity College, he became a journalist and author, famous for both his sensationalist novels and his supernatural tales. For In a Glass Darkly Le Fanu used a technique common in gothic fiction by having a narrator/editor who presents past documents, in this instance of mysterious medical case histories from the papers of the nowdeceased Dr Hesselius. The latter is a European 'metaphysical physician' with Swedenborgian leanings who likes to investigate curious psychological phenomena. He considerably resembles the later Professor Van Helsing from Bram Stoker's Dracula.

In the story Green Tea, letters to a non-medical friend describe the case of the Rev. Mr Jennings whom Dr Hesselius meets first at a small soirée in London. The Reverend is a kind and pleasant man, but

"when he goes down to his vicarage in Warwickshire, to engage in the actual duties of his sacred calling, his health soon fails him, and in a very strange way ... it has happened three or four times, or oftener, that after proceeding a certain way in the service, he has on a sudden stopped short, and after a silence, apparently quite unable to resume, he has fallen into solitary, inaudible prayer, his hands and his eyes uplifted, and then pale as death, and in the agitation of a strange shame and horror, descended trembling, and got into the vestry-room, leaving his congregation, without explanation, to themselves.'

Dr Hesselius notes a strange quirk:

'Mr Jennings has a way of looking sidelong upon the carpet, as if his eye followed the movements of something there. This, of course, is not always. It occurs now and then. But often enough to give a certain oddity, as I have said, to his manner."

The two talk, and Dr Hesselius promises to pass to Mr Jennings a copy of his book Essays on Metaphysical Medicine, which the latter is eager to re-read. Subsequently, rather in the manner of a later medical sleuth, Sherlock Holmes, Dr Hesselius amazes his hostess by surmising correctly that Mr Jennings is unmarried, that he had been writing a book, but stopped, and that he 'extravagantly' liked green tea, but has given it up. Subsequently Dr Hesselius visits Mr Jennings, and as he is engaged with a visitor, is shown into his library. There he picks up a volume by Swedenborg, annotated by Jennings, which includes the comments:

'When man's interior sight is opened, which is that of his spirit, then there appear the things of another life ... Evil spirits (may) present themselves, by "correspondence," in the shape of the beast . . . which represents their particular lust and life, in aspect direful and atrocious.

Mr Jennings asks for a professional medical consultation, as he has been disappointed by the materialist approach of a Dr Harley, and tells his story. He had been studying deeply in an attempt to write a book on 'the religious metaphysics of the ancients', and in doing so often worked late into the night imbibing large quantities of green tea. He noticed no ill effects until he became aware of the repeated presence of a small black monkey, with glittering eyes, who regarded him malevolently; and now the animal has become even more intrusive, making blasphemous remarks when he attempts to pray and perform his religious duties.

Dr Hesselius advises that 'in your case ... the veil of the flesh, the screen, is a little out of repair, and sights and sounds are transmitted' but that the 'thing that infests you ... can have no power to hurt you, unless it be given from above'. However, he would give the matter careful thought.

At a later consultation, Mr Jennings' experiences have worsened. The terrifying monkey has recently ordered him to throw himself down a mine shaft, a command he was only able to resist as he was accompanied by his niece. Again Dr Hesselius assures him that the cause must be physical, and that he should not, as he seems to, believe that he had 'been delivered over to spiritual reprobation'.

Unfortunately, Dr Hesselius' risk assessment has been weak, and the next time he is called his patient has been found dead, having cut his own throat. He reflects on the case to his correspondent, and concludes he has not been at fault. First: ' I have met with, and treated, as my book shows, fifty-seven cases of this kind of vision ... And in how many of these have I failed? In no one single instance'. He explains the mechanism by which the 'inner eye' is opened: nervous fluid, which is 'spiritual, though not immaterial' may be disturbed in its equilibrium by substances such as green tea, and form 'a surface unduly exposed, on which disembodied spirits may operate'. Such a condition may be remedied by the application of cold, such as 'iced eau-de-cologne'. However, in this case he had not yet advanced to treatment.

\section{Furthermore:}

'Poor Mr Jennings made away with himself. But that catastrophe was the result of a totally different malady, which, as it were, projected itself upon the disease which was established ... the complaint under which he really succumbed, was hereditary suicidal mania.'

The real life medico-psychologist Henry Maudsley had of course a different view of Swedenborg, whom he considered to have chronic mania, perhaps also with epilepsy. As a materialist, he might well have agreed with Hesselius's final diagnosis, whereas we, the readers, remain unnerved by the thought of the inescapable malevolent simian. 